This is a self-archived version of an original article. This version may differ from the original in pagination and typographic details.

Author(s): Paananen, Mika; Aro, Tuija; Närhi, Vesa; Aro, Mikko

Title: Group-based intervention on attention and executive functions in the school context

Year: 2018

Version: Accepted version (Final draft)

Copyright: @ 2017 Informa UK Limited, trading as Taylor \& Francis Group

Rights: In Copyright

Rights url: http://rightsstatements.org/page/InC/1.0/?language=en

Please cite the original version:

Paananen, M., Aro, T., Närhi, V., \& Aro, M. (2018). Group-based intervention on attention and executive functions in the school context. Educational Psychology, 38(7), 859-876.

https://doi.org/10.1080/01443410.2017.1407407 
Group-based Intervention on Attention and Executive Functions in the

\section{School Context}

Mika Paananen MA ${ }^{1,3}$, Tuija Aro $\mathrm{PhD}^{2,3}$, Vesa Närhi $\mathrm{PhD}^{1}$, and Mikko Aro $\mathrm{PhD}^{1}$

${ }^{1}$ University of Jyväskylä, Department of Education, Jyväskylä, Finland

${ }^{2}$ University of Jyväskylä, Department of Psychology, Jyväskylä, Finland

${ }^{3}$ Niilo Mäki Institute, Jyväskylä, Finland 


\title{
Group-based Intervention on Attention and Executive Functions in the School
}

\section{Context}

\begin{abstract}
The objective of the study was to examine the effects of a group-based behavioural, cognitive and skills training intervention (Maltti) provided in schools for elementary school pupils with attention and executive function (EF) deficits. The treatment effects were identified by comparing an intervention group $(n=46)$ with a waitlist control group $(n=26)$. Specific effects of the intervention on behavioural deficits in attention and EF in a classroom setting as well as on academic skills were examined. Our analysis indicated that significant intervention effects could be found in the behavioural manifestation of attentional and executive skills in the classroom setting among children $(\mathrm{n}=30)$ who were evaluated as having moderate symptoms in the pre-intervention assessment. Positive effects of the intervention were also observed in arithmetic and reading skills. The severity level of pre-intervention attention and EF deficits did not moderate the results observed in the academic skills tests. The results of this study suggest that a combination of behavioural, cognitive and skills training methods applied in a school context can be effective in reducing attention and EF problems and enhancing the academic performance of children with attention and EF deficits.
\end{abstract}

Keywords: attention deficits; executive function deficits; intervention; treatment efficacy 
Problems of attention and executive functions are extremely common, and approximately 5\% of the school-age population meets the criteria for attention deficit hyperactivity disorder (ADHD) (Polanczyk, de Lima, Horta, Biederman, \& Rohde, 2007). In the school setting, ADHD causes significant social, behavioural, and functional impairment, as well as poor academic performance (Barkley, 1997; Murphy, Barkley, \& Bush, 2002). Even among children who do not have a formal diagnosis of ADHD, symptoms and features of ADHD are associated with adverse academic outcomes (Loe \& Feldman, 2007).

Problems in the executive functions (EFs) overlap with attention deficit problems, and thus they are included as an essential component in contemporary models of ADHD (Hinshaw \& Arnold, 2015). It has been suggested that both ADHD symptoms and deficits in EFs reflect the hypoactivity and immaturity of frontal brain structures (Rapport, Orban, Kofler, \& Friedman, 2013; Sonuga-Barke, 2002). The approaches used in different studies to measure deficits in attention and EFs include rating the diagnostic behavioural core symptoms of attention deficit (inattention, impulsivity and hyperactivity) (Sonuga-Barke et al., 2013), the behavioural manifestations of EFs (Evans et al., 2014), performance in cognitive laboratory tests (Rapport et al., 2013), and performance in neuropsychological tests (Evans et al., 2014), all of which tap into deficits in these functions.

Learning situations in school make multiple demands on children's EFs (e.g., inhibitory control, behavioural control, sustained and selective attention, problem-solving and planning; Diamond, 2013). Since children with ADHD frequently have problems with ontask behaviour, which reflects their deficits in the EFs (Barkley, 1997; Sonuga-Barke, 2002), they are at risk for deficits in academic achievement (Rapport et al., 2013). It is therefore important that interventions for attention deficits not only aim to reduce the social and behavioural problems caused by the ADHD symptoms, but that they also aim to improve the EFs required to succeed in the academic setting. In a similar vein, outcome measures that 
detect changes in learning-related functions should be used in intervention studies as they assess the age-relevant capabilities needed in the everyday context (Evans et al., 2014). In the present study, our interest was to explore the effects of an intervention aimed at attention and $\mathrm{EF}$, and in particular, the behavioural manifestations of EFs, that is, in relation to on-task behaviour in the classroom setting and in relation to basic academic skills.

Medical and behavioural treatments are effective in reducing the core symptoms of attention deficit and disruptive behaviour, but these methods have not been shown to have strongly positive academic or educational outcomes (Hinshaw \& Arnold, 2015; Loe \& Feldman, 2007). The behavioural improvement gained with contingency-based behavioural interventions is often observed only in the intervention setting where the contingencies are delivered, and generalization across different settings is limited (Abikoff, 2009). Cognitivebehavioural interventions for children with ADHD, or with characteristic ADHD behaviour, have shown conflicting results: they have variously been shown to be ineffective (Pelham \& Fabiano, 2009), promising (Toplak et al., 2008; Kearns \& Fuchs, 2013; Sonuga-Barge et al., 2013), effective in single-case studies (DuPaul, Eckert, \& Vilardo, 2012,), and effective with a subclinical level of deficits (Miller \& Hinshaw, 2012) in reducing ADHD and other behavioural symptoms. Traditionally, cognitive-behavioural methods utilize self-monitoring and self-control, but these are seen as the core weaknesses of children with attention deficits, so this might be one reason why these interventions have shown limited effectiveness (Schultz, Storer, Watabe, Sadler, \& Evans, 2011).

To promote a generalization of the effect of an intervention to academic learning, the delivery setting should be relevant to the objectives of the intervention and the focus of the intervention should be on the behaviours and skills necessary for children to function adequately in their everyday settings (Abikoff, 2009). Due to the high rate of academic difficulty among children with attention and EF deficits, the first line of treatment should be 
interventions developed for and implemented in the school setting (DuPaul et al., 2012; Evans, Owens, \& Bunford, 2014; Schultz et al., 2011). There is strong evidence to show that among children with ADHD and children at-risk for academic difficulties academic interventions and explicit skills-teaching that focus on academic instructions and the use of materials are associated with positive academic outcomes. However, they do not necessarily result in behavioural change (DuPaul et al., 2012; Kearns \& Fuchs, 2013).

To overcome the limitations of each intervention method, DuPaul et al. (2012) suggest that the incorporation of elements from several interventional approaches could address the academic, behavioural and EF difficulties of children with ADHD symptoms more effectively than the use of any single intervention strategy alone. Comprehensive methods, such as specific skills training combined with behavioural (Abikoff et al., 2013; Langberg, Epstein, Becker, Girio-Herrera, \& Vaughn, 2012) or cognitive elements (Deaño, Alfonso, \& Das, 2015) and implemented in a school context have shown promising results in both behaviour and academic skills in children with attention deficits, but more research is needed.

In order to prevent unwanted consequences and the accumulation of problems, supportive arrangements in schools should be started as soon as problems of attention and EF are noticed (ADHD: Current Care Guidelines Abstract, 2017). This approach is also supported by findings showing that academic skills such as reading and mathematics are strongly correlated with the development of EFs (Best, Miller, \& Naglieri, 2011). Overall, there is a need to develop and to study empirically comprehensive methods that can ameliorate both the behavioural and academic problems of children with attention and EF problems that interfere with their school performance. These methods should promote both the EFs and the ability to function adequately in a school setting. Furthermore, there is a need 
to explore the effectiveness of these combined behavioural, cognitive and skills training approaches when implemented in a natural setting (i.e., the school context).

In this study, we aimed to implement an experimental attention and EF intervention in a normal Finnish elementary school setting and in accordance with the customary special education procedures of Finnish schools. This approach was appropriate because in Finland deficits in learning, attention and EFs as observed by teachers are considered eligibility criteria for the provision of special educational support and intervention by the school. In other words, no medical diagnosis is needed. Most special education support and instruction is given in regular schools, either in general education classrooms or in small groups. Special education is employed extensively in Finland, with almost one fourth of pupils participating in special education at some point during their elementary or middle school years (Björn, Koponen, Aro, Fuchs, \& Fuchs, 2015). In line with the principles and procedures of Finnish special education, participation in the intervention for this study did not require a diagnosis of ADHD.

The group-based and comprehensive Maltti ("Patience”) intervention (Paananen, Heinonen, Knoll, Leppänen, \& Närhi, 2011) used in the present study is based on previous intervention studies and findings among children with ADHD. Maltti is designed to be implemented in a school context as part of the special education support provided for children with problems in attention and EFs. Provided in manual form, it combines behavioural management techniques with methods that focus on cognitive and executive skills building (see Table 1). Behavioural management in Maltti involves a reward system, praise and positive attention to increase the occurrence of target behaviours and strategies (Evans et al., 2014; Toplak et al., 2008). The cognitive and learning-related executive skillsbuilding components of Maltti aim to improve the executive processes required in learning (Abikoff, 2009; Das, Parrila, \& Papadopoulos, 2000). 
The Maltti programme aims to improve on-task skills and behaviours that a child can use and modify in different learning contexts (Abikoff, 2009) and thereby achieve generalization of these treatment effects to task situations outside of the intervention setting (i.e., classroom and learning settings). In the present study, the main interest was in exploring the effects of the intervention on children's behaviour in the classroom setting and on their learning, particularly in relation to attentional functions, EFs, and academic skills. The specific research questions concerned the effects of the intervention on (a) attention and EFs and (b) the development of academic skills (reading and arithmetic fluency). Based on earlier research (Abikoff et al., 2013; Deaño et al., 2015; DuPault et al., 2012), we hypothesized that the comprehensive Maltti programme would have an effect on attention and EFs.

Furthermore, based on the finding that enhanced EF is associated with positive effects on reading and arithmetic (Best et al., 2011) we anticipated it would affect the development of reading and mathematical skills.

We also examined the effects of symptom severity in attention and EF deficits on intervention outcomes. Owens et al. (2003) and Langberg et al. (2010) have previously shown that baseline symptom severity may have an effect on intervention outcomes. Owens et al. (2003) found that high levels of initial severity were associated with poor treatment outcomes. Langberg et al. (2010) showed that an intervention combining both behavioural treatment and medication was more effective for children with low to moderate symptom severity (the $75 \%$ of the sample with less severe symptoms) as compared to other interventions. However, while children with high symptom severity (the highest $25 \%$ ) showed large improvements in target behaviour, there were no differences in the effectiveness of the different interventions (medication, behavioural treatment, a combination of the two, and community care; Langberg et al., 2010). Based on the findings of Owens et 
al. (2003) and Langberg et al. (2010), we hypothesized that baseline symptom severity would moderate the effect of the intervention.

\section{Method}

\section{Participants}

Ninety children from grades one to six (ages 7-12) participated in the study. Sixty-two of them (10 girls and 52 boys) participated in the attention and EF intervention (the Maltti programme) and twenty-eight children ( 6 girls and 22 boys) were in a waitlist group that served as a control for the study. Two boys from the intervention group discontinued their participation due to their changing schools. All children were Caucasian and all but one (a Russian) spoke Finnish as their mother tongue.

The children in the intervention group came from 14 schools in ten different towns and municipalities in Southern, Central, and Eastern Finland. School districts were diverse (i.e., urban, suburban, and rural). The control group children came from four schools situated in urban areas of two small towns in Central and Eastern Finland and were waitlisted to participate in the intervention (the Maltti programme) at a later date. As differences between schools and in students' performances between schools are very small in Finland (Linnakylä, Välijärvi, \& Arffman, 2011), it was assumed that there was no variation between students' schooling and abilities.

The initiative to include a particular child in the intervention came from the classroom teachers, as is the common practice in Finland, and the final selection of the students was conducted in a joint discussion between the researchers and the intervention providers (usually the school's special education teacher and/or school psychologist). Inclusion criteria were the same for both the intervention group and the control group: (1) the children were identified in classroom settings as showing symptoms of attention and/or EF deficits, and (2) these deficits caused problems in their daily school routines and learning 
situations. The parents' consent was obtained for the children to participate in both the intervention and the study. Participation in the study was voluntary.

Intervention participants were in grades $1-6$ and control participants in grades 1-5. All participants followed the normal school curriculum, but $48 \%$ of the intervention group and $50 \%$ of the control group children already received special education support (in addition to the Maltti intervention to be received by the intervention group). For $13 \%$ of the children from the intervention group and $11 \%$ from the control group, special education had been arranged for both behavioural and learning difficulties. Special education in mathematics was given to $6 \%$ of children in the intervention group and $14 \%$ of children in the control group, and for reading to $29 \%$ in the intervention group and $25 \%$ in the control group. Ten children $(16 \%)$ in the intervention group and three $(11 \%)$ in the control group had a diagnosis of ADHD. Eight of these children were receiving ADHD medication (Methylphenidate): six from the intervention group and two from the control group. The medication status of the participating children did not change during the period of the study.

\section{Materials}

\section{Maltti programme}

The Maltti programme (Paananen et al., 2011) is a theory-driven, manualized intervention developed for use in a school setting with elementary school aged children with problems in attention control and EFs. It is a group-based, behavioural, cognitive, and skills-building approach (see Table 1). The manual provides detailed instructions for 20 sessions.

The behavioural methods (i.e., feedback and contingency management) of the Maltti programme aim to support sustained attention and persistence and thus lengthen on-task working periods. This is based on the motivational dysfunction model, which claims that ADHD is related to attentional problems in situations where reinforcements are delivered infrequently (Aase \& Sagvolden, 2006), and it is also related to an aversion to delayed reward 
(Sonuga-Barke, 2002) leading to difficulties in sustaining attention (Aase \& Sagvolden, 2006). Contingency management is also used to reinforce practiced skills and their use during the sessions. The methods used in Maltti to enhance cognitive and learning-related executive skills seek to improve cognitive control processes, such as the skill to focus on relevant information and on-task behaviour. The tasks that are used require inhibitory control and are intended to develop attention control and prolong processing time in task situations. This is based on the assumption that children with ADHD have inhibition difficulties (Barkley, 1997) and that they observe cues for a shorter amount of time and use less information for the processing of actions (Milch-Reich, Campbell, Pelham, Connelly, \& Geva, 1999). Through modelling and strategy training, Maltti supports executive skill building and the control of on-task behaviour (e.g., task planning skills, organizing of task performance and materials, and planning check out) (Abikoff et al., 2013; Deaño et al., 2015). This is based on the assumptions that improvement in the ability to focus on relevant information (Abikoff, 2009), enhanced strategy use, and better self-organization in task situations (Abikoff et al., 2013; Das, Parrila, \& Papadopoulos, 2000; Langberg et al., 2012) will all enhance children's ontask behaviour and ultimately their academic performance.

The programme consists of three parts comprising exercises and tasks emphasising different aspects of on-task behaviour and EFs: inhibition and attention control ( 5 sessions), inhibitory control and planning (4 sessions), and strategy training (11 sessions). At the onset of the programme, exercises are simple pencil and paper visual search tasks, auditory attention tasks, and problem solving tasks with visual materials that aim to introduce the participants to working routines and the elements of strategic skills. As the programme progresses, the tasks become more closely related to actual schoolwork. Mathematical reasoning tasks, reading comprehension tasks, social skills, and game practises target improvement in both the executive functions and adaptive behaviour in the classroom setting. 
During the sessions, every task is initiated with verbalisation, modelling, and scaffolding. Selective and sustained attention and inhibitory control are emphasised throughout the programme (see also Table 1).

In the present study, the teachers had structured guidelines for running each session and for the systematic use of feedback and verbal praise. During the intervention, the desired behaviour and activities were reinforced by a token system. The behavioural expectations of the group meetings were explicit. Every treatment session had the same structure and routines and included four programme topics: orientation, practices, reward management (tokens), and a play or game exercise (except for the first session, which had three topics). Each session lasted 60 to 75 minutes. Sessions started with a short warm-up during which every participant was acknowledged. Next, the day's tasks and the reasons for receiving rewards were presented. After performing the actual on-task practices, processes related to task completion were reinforced by tokens. The session ended with game practices, which were intended to be both a fun ending to the meeting while also presenting demands for executive functions. Selfefficacy was promoted by explicit supportive feedback and by controlling the level of difficulty of tasks. The difficulty levels of the tasks varied as a function of the grade level in the tasks requiring reading and math skills.

Treatment fidelity was evaluated by means of provider interviews and checklists filled in by the providers after each session. The checklist covered the topics covered during each session and was used to verify if the sessions had included all the intended four topics. In addition, all providers were interviewed, which allowed for the evaluation and confirmation of fidelity information. The percentage of topics covered in each session was calculated on the basis of the checklists: $80 \%$ coverage of topics was set as a limit of acceptable fidelity. Intervention providers were asked to report drop-outs and non-attendance of participants. 


\section{Measures}

Attention and EFs. Problems of attention and executive functions in school were assessed using a norm-referenced teacher-completed rating scale, the ATTEX questionnaire (Klenberg, Jämsä, Häyrinen, Lahti-Nuuttila, \& Korkman, 2010). The ATTEX has high internal consistency (total score $\alpha=0.98$ ) and good criterion validity (Klenberg et al., 2010). It has 55 items which cover ten different areas of attention and EFs: distractibility (four items), impulsivity (nine items), motor hyperactivity (seven items), directing attention (five items), sustaining attention (six items), shifting attention (four items), initiation (five items), planning (four items), execution of action (eight items), and evaluation (three items). The items are rated on a three-point scale: 0 for "not a problem," 1 for "sometimes a problem," and 2 for "often a problem." Total score range from 0 to 110 with higher score indicating greater symptom severity.

Academic skills. Reading performance was assessed with the Word Recognition Test (Lindeman, 1998) and the Luksu Reading Fluency Test (Salmi, Eklund, Järvisalo, \& Aro, 2011). The Word Recognition Test assesses basic reading skills. It consists of 78 word-chains containing two to four words. The child is asked to mark with a pencil word boundaries within each chain (e.g., minä/ei/me/tulla; me/no/us/come). Children are asked to proceed as fast as possible, with a time limit of 3 minutes and 30 seconds. The score is the number of correctly identified words. Correlations in the range of 0.63 to 0.73 have been found between teacher-rated reading performance and the Word Recognition Test (Leppänen, Aunola, \& Nurmi, 2005). The test has two parallel versions, which were used alternately in the assessments (with this sample, correlation between the parallel versions was 0.90).

In the Luksu Reading Fluency Test (Salmi et al., 2011), children are provided with 70 simple sentences and asked to read them as fast as possible and then to decide whether they are true or false. The time limit is two minutes. The score is the number of correct answers. 
The test has three parallel versions, and at each assessment point a different version was used. Cronbach's alpha ranges from 0.94 to 0.95 for all versions.

Arithmetic skills were assessed with three tests: the Addition Fluency Test (Koponen \& Mononen, 2010a), the Subtraction Fluency Test (Koponen \& Mononen, 2010b), and the Basic Arithmetic Test (Aunola \& Räsänen, 2007). The Addition and Subtraction Fluency Tests consists of easy addition and subtraction tasks on paper. Both tests have a time limit of two minutes and the test score is the total number of correct responses. This test also has three parallel versions, which were rotated across assessments. Cronbach's alpha is available for the first two of the parallel tests: 0.88 for the Addition Fluency Test and 0.90 for the Subtraction Fluency test. In the present study, the sum score of the Addition and Subtraction Tests was used as the Arithmetic Fluency Test (for this sample, Cronbach's alpha was 0.87).

The Basic Arithmetic Test contains 28 items on paper (14 addition and 14 subtraction items) of increasing difficulty. Children are asked to proceed as fast as possible. The total number of correct answers during the time limit of three minutes forms the test score. Testretest reliability for this test is 0.86 (Räsänen, Salminen, Wilson, Aunio, \& Dehaene, 2009).

\section{Procedure}

Intervention providers and training.

The Maltti programme was delivered at schools by school personnel. The intervention providers consisted of teachers (seven), special education teachers (seven), and school psychologists (four). Teacher education is at the same standard in every part of Finland and all basic education teachers are required to have a master's degree. The high standard of education of the providers ensured adequate staff proficiency in the implementation of the Maltti programme. Altogether, there were 14 intervention groups (one group in each participating school) consisting of four to seven participants. The intervention groups had 18 to 20 sessions held once per school week. The intervention took place during or after school 
hours. The intervention period lasted from October (the middle of the autumn semester) to April (the second-to-last month of the spring semester).

The intervention providers were recruited from participants in the Maltti intervention training. This cost-free training, organized by the Finnish Board of Education and the Niilo Mäki Institute, targets school staff, teachers, special education teachers, and school psychologists. The intervention providers for ten of the groups participated in the Maltti training, consisting of four six-hour training sessions, two before the intervention period (in October) and two during it (in December and March). Providers started their intervention groups after the first two training sessions. The intervention providers for ten of the groups in the study were novices in terms of the Maltti programme, and had got to know the programme only during the training. The providers in four of the groups had received their training earlier, and at the start of the study, they were already familiar with the method and had experience in running a Maltti intervention. They started the intervention earlier (in the preceding school year) than the other ten groups. The providers of these four groups received guidance from the research team only on the assessments. Twelve of the groups had two intervention providers and two groups had just one provider. In three groups, the intervention provider was also the children's classroom teacher. The waitlist control group was recruited by teachers attending the later Maltti intervention training. The control group started its intervention only after the follow-up assessments. Because the groups receiving the Maltti intervention training were predefined, we had to make some compromises with design, and thus the ideal experimental design (e.g., with randomization and blinded participants) was not applicable.

\section{Screening and assessment procedure}

Pupils with attention and EF deficits that affected their school performance were identified by their class teachers in consultation with the intervention providers. The parents gave written 
consent for their children to participate in the study. After that, pre-intervention questionnaires were sent to both parents and teachers. The parents of four of the children identified for participation in the intervention did not consent to their child participating in the study.

The pre-intervention data was gathered in the autumn before the interventions started. Post-intervention assessments were conducted the following spring and subsequent follow-up assessments the following autumn, one month after the beginning of the school year. There was a period of seven months between the pre- and post-intervention assessments, and five months between the post-intervention and follow-up assessments. For each assessment the classroom teachers filled in the attention and EF questionnaires, while parents filled in a questionnaire concerning their child's possible diagnoses and current medication, and the children were assessed for their reading and arithmetic skills. In 11 groups out of the 14, the classroom teachers were not involved with the intervention. In the other three groups, the classroom teacher was an intervention provider. Parents were also asked about their own level of education: (1) compulsory education up to the completion of grade 9, (2) senior high school, (3) vocational school, (4) three-year education at a college and (5) university education.

Assessments of the children's academic performance were conducted at preintervention, post-intervention, and follow-up by the research team, the local school psychologists, or by special education teachers in cooperation with the research team. The pre-intervention assessment was performed individually. Due to time restraints, the postintervention and follow-up assessments were done in small groups of two to four children. These academic tests were not conducted with the four groups (14 participants) that had started the intervention during the preceding school year. 


\section{Data analysis}

First, the groups were compared at baseline for different variables (age, grade level, attention and EF problems as rated by teachers, reading skills, math skills, and parents' education) with one-way ANOVA to study their equivalency. Second, mixed-model ANOVAs were used to analyse changes in outcome measurements, ATTEX, and academic skills at the assessment time points (pre-intervention, post-intervention, and follow-up) as within-subjects factors and with the group as a between-subjects factor. Additional pairwise comparisons were made between pre- and post-assessment time-points to investigate possible immediate intervention effects. Third, moderation analyses were performed using the Johnson-Neyman method (Hayes, 2013). This method made it possible to study the extent to which the pre-intervention level of symptoms (pre-intervention ATTEX score) was associated with the outcomes (postintervention ATTEX score and academic skills scores), that is, to establish regions of significance associated with the changes observed in the post-ATTEX or academic test scores of the control and intervention groups. Fourth, once the subjects that were in the region of significance (in terms of difference between groups) were analysed through moderation analyses (Johnson-Neyman), the mixed-model ANOVA was used to analyse the changes in outcome measurements, ATTEX, and academic skills, with the assessment time points (preintervention, post-intervention, and follow-up) as the within-subjects factors and the groups as the between-subjects factor.

\section{Results}

\section{Attendance and Fidelity}

Attrition and the collected data are presented in Table 2. There were no differences between groups at the baseline in terms of age, grade level, attention and EF problems, reading skills, math skills, or parents' education (Table 3). 
According to the checklist information (and confirmed with interviews), the percentage of the treatment contents for the four topics covered in each session varied from $74.68 \%$ to $100 \%$. Two groups had fidelity of less than $80 \%(74.68 \%$ and $78.48 \%)$, even though these groups both had the full 20 sessions. These groups did not follow the planned structure for the intervention sessions: the last topic of the session programme (the play/game exercise) was completed by these groups in only $10.5 \%$ and $20 \%$ of the sessions, respectively. These two groups with poor fidelity (nine participants) were excluded from the analyses.

\section{Change in Attention and EFs}

The means and standard deviations from the pre-, post- and follow-up assessments are presented in Table 4. The mixed-model ANOVA result for the interaction of time (preintervention, post-intervention, and follow-up) and the group for the total ATTEX score was not significant $\left(\mathrm{F}(2,68.00)=1.57 ; \mathrm{p}=.22 ; \eta_{\mathrm{p}}{ }^{2}=.04\right)$. The pairwise comparison of time (preand post-assessment) and group did not quite reach significance $(\mathrm{F}(1,70.00)=3.14 ; \mathrm{p}=.08$; $\left.\eta_{\mathrm{p}}^{2}=.04\right)$

The Johnson-Neyman method (Hayes, 2013), which was used to determine the extent to which pre-intervention symptom severity (ATTEX score) influenced the intervention effect, showed significant group differences for $58.33 \%$ of participants. The analysis revealed that when pre-intervention ATTEX scores were between 14 and 60, there was a significant relationship between pre- and post-intervention ATTEX scores, and within this score range children in the intervention and control groups progressed differently. However, when the pre-assessment ATTEX score was lower than 14 points or higher than 60 points, there were no significant relationships between the ATTEX pre- and post-intervention assessment. This indicates that children with either high or low pre-intervention ATTEX problem scores showed no difference subsequent to the intervention. There was only one child in each group 
that had a score lower than 14 in the ATTEX pre-assessment, and in the post-assessment they both showed a small change in their points (from 9 to 11 and from 1 to 5), indicating a low behavioural problem rating by their teacher in both the pre- and post-assessments. An additional mixed method ANOVA for the ATTEX total score was applied to the subjects $(\mathrm{n}=$ 42) who were in the region of significance. The results revealed that the interaction of time (pre-intervention, post-intervention, and follow-up) and group was significant for the ATTEX total score $\left(\mathrm{F}(2,39)=10.09, \mathrm{p}<.000, \mathrm{\eta}_{\mathrm{p}}^{2}=.34\right)$, suggesting positive development in the intervention group (intervention group pre-assessment $(n=30), M=41.00(S D=11.98)$, post-assessment $\mathrm{M}=32.97(\mathrm{SD}=15.44)$ and follow-up $\mathrm{M}=35.65(\mathrm{SD}=23.50)$; control group $(\mathrm{n}=12)$, pre-assessment $\mathrm{M}=43.92(\mathrm{SD}=12.35)$, post-assessment $\mathrm{M}=58.00(\mathrm{SD}=$ 18.57) and follow-up $\mathrm{M}=53.88$ ( $\mathrm{SD}=21.64)$ ). Pairwise comparisons between the three time points revealed significant differences between the groups between the pre- and postintervention assessments $\left(\mathrm{F}(1,40)=19.94, \mathrm{p}<.000, \mathrm{\eta}_{\mathrm{p}}{ }^{2}=.33\right)$ as well as between the preand follow-up assessments $\left(\mathrm{F}(1,40)=4.38, \mathrm{p}=.043, \mathrm{\eta}_{\mathrm{p}}{ }^{2}=.10\right)$. There was no significant interaction for time and group in relation to the post-intervention and follow-up assessments.

\section{The results for academic skills}

The scores for academic tests at the three assessment time points are presented in Table 5. The mixed method ANOVA indicates that the interaction of time (pre-intervention, postintervention, and follow-up) and group in the Word Recognition Test almost achieved significance $\left(\mathrm{F}(2,60)=3.06, \mathrm{p}=.054, \mathrm{\eta}_{\mathrm{p}}{ }^{2}=.09\right)$. Pairwise comparisons revealed that the intervention group had a significantly greater gain in the Word Recognition Test between the pre- and post-intervention assessments $\left(\mathrm{F}(1,63)=4.61, \mathrm{p}=.036, \mathrm{\eta}_{\mathrm{p}}^{2}=.07\right)$. Interaction between time (pre-intervention, post-intervention, and follow-up) and group in the Arithmetic Fluency Test scores was not significant, but a pairwise comparison did reveal significant interaction between the pre- and post-assessment $\left(F=(1,63)=5.64, \mathrm{p}=.021, \mathrm{\eta}_{\mathrm{p}}{ }^{2}=.08\right)$, 
indicating that during this period the intervention group improved more than the control group. No significant effects were found for the Basic Arithmetic Test or the Luksu Reading Fluency Test. Moderation analysis revealed that pre-intervention symptom severity (ATTEX score) did not moderate the development of academic skills.

\section{Discussion}

The current study examined the effects of behavioural, cognitive, and skills training intervention (the Maltti programme) in a normal elementary school setting with children with attention and EF deficits as identified by their teachers. The intervention was implemented by school personnel as part of the special education support offered in Finnish schools, and it aimed to improve executive skills and functioning in task situations in the school setting. Positive effects from the treatment were found in attention and EF and also in academic skills, but the improvement in attention and EF varied according to the initial severity of the problem.

As expected on the basis of the findings by Langberg et al. (2010) and Owens et al. (2003), symptom severity moderated the observed effects of the intervention on attention and EF. Moderation analysis indicated differences in the progress of attention and EF between the Maltti group and the control group in relation to the pre-intervention severity levels of symptoms of attention and EF deficits. Positive intervention effects in relation to attention and EFs in the classroom setting were found among children from the Maltti intervention group who were identified as having moderate symptoms in the pre-intervention assessment. It has been suggested that children with high symptom severity are less likely to show differences in treatment effect (Owens et al., 2003). It can be assumed that children with high symptom severity are "resistant" to treatment effects (Miller \& Hinshaw, 2012). These children may therefore need more individualized or prolonged intervention before behavioural change can be detected in the classroom setting. 
A positive intervention effect was found in both arithmetic fluency and basic reading skills between the pre- and post-intervention assessments. These results were not moderated by the pre-intervention symptom severity. The long-term gains (from the pre-intervention to follow-up assessments) were greater for the intervention group in relation to the academic skills mentioned above than they were for the control group, but the difference did not reach significance. The intervention effect could be seen only in simple academic tasks, that is, in basic reading skills (word recognition) and in basic math fluency. In more complex tasks or in tasks that demand set changes (sentence reading and comprehension or arithmetic reasoning) the groups progressed equally. Altogether, these results are in line with earlier findings showing that comprehensive interventions implemented in school with specific goals (Abikoff et al., 2013; Deaño et al., 2015; Langberg et al., 2012) are effective in reducing attention and EF deficits and in improving performance in tasks tapping basic academic skills.

To maximise treatment benefits, treatment goals should be adequately considered and sufficient opportunities should be given to practice and develop competence; these can then facilitate learning (Abikoff, 2009). The Maltti programme's focus is on a fairly limited set of behaviours and skills: it aims to help children focus on relevant information, thereby prolonging the time of sustained attention in order to enhance a child's attention span in task situations (Abikoff et al., 2009). It can be assumed that the benefits identified arise from improved inhibitory control in on-task situations and prolonged time used for processing required actions. In addition, the modelling practices aimed at conscious use of strategies, while the structuring of task fulfilment probably improved the executive skills needed to manage task situations in school and to control on-task behaviour.

It should be remembered that significant effects are not necessarily clinically meaningful. At the group level, the mean for the ATTEX total scores did not reach the level 
of 'normality', and there was a large variation in the extent to which the children's scores changed. Nevertheless after the intervention, the mean score for ATTEX in the moderate severity group dropped below the level that is considered a cut-off score for correctly identifying a diagnosis of ADHD for boys (36.5 points; Klenberg et al., 2010). It can hardly be expected that the intervention would normalize the behaviour of the children or remove their core deficits, such as poor control of vigilance or delayed reward aversion. However, we can claim that the intervention can reduce symptoms and behavioural impairments. These changes can further affect academic performance, and this is pedagogically meaningful. If a teacher registers favourable change in a child's behaviour, it may facilitate positive development in the long run.

Another essential issue in treatment studies is generalization across settings and skills. In the present study, no attempts were made to include treatments occurring in other settings where the children operate daily (i.e., in the classroom or home). Despite this, the generalization of the intervention effects to both the classroom behaviour (of children with moderate severity symptoms) and academic functioning was evident.

The participation of three classroom teachers as intervention providers may have had an effect on their questionnaire ratings. It is also possible that these teachers implemented the intervention principles in the classroom setting as well, thereby producing a larger intervention effect. Additional analyses revealed that in the moderate symptom group there were higher gains in attention and $\mathrm{EF}$ in the classroom setting for the pupils of these particular teachers. However, when the main analysis was replicated without these children with the possible proximal effect (again among a group of children with moderate severity symptoms), the results indicated a significant time $\mathrm{x}$ group interaction.

The findings regarding improvements in arithmetic and reading tests (suggesting a transfer effect to academic skills) are interesting, since they can be interpreted as being 
independent of the possible bias caused by teachers being aware of the intervention status. Gordon et al. (2006) have proposed that functional assessments, such as academic tests, should be used to evaluate the adverse effects of attention deficits as well as intervention effects. Previous studies have demonstrated that EF tasks correlate with math and reading performance and that EF-related cognitive processes (e.g., impulse control, self-monitoring, and plan generation) are relevant for both math learning and reading (Best et al., 2011; Jacob \& Parkinson, 2015). The present findings are in line with this assumption: as interventions promote ability in attention and EFs, they also facilitate fluency in mathematical and reading performance.

It is necessary to point out some limitations of the study: First, the sample size was quite small, which is often the case with studies in natural settings. Poor fidelity further reduced the sample by nine participants. A larger sample would have given more power to the analyses and limited the effects of the wide variance of outcome measurements noted and of the potential heterogeneity of the sample. Second, randomization was not possible, and a quasi-experimental design was employed in the study, thus threatening the equivalency of the intervention and control groups. Nonetheless, the groups had equal age and class levels, nearly the same gender ratio, and a comparable ratio of children who received special educational support at school or were diagnosed and medicated. Also, there were no statistically significant differences between the groups in the outcome measures in the pretreatment assessment. Third, because teachers were aware of the intervention status of particular children, their ratings were subject to an expectancy effect. In the future, a multiinformant method should be used to avoid possible bias. Lastly, there was a leak of intervention content to the control group. The control group's future intervention providers had received the Maltti training during the previous spring, before the follow-up assessment, and interviews with the control group's school principals revealed that three of their four 
schools had started to foster pupils' task engagement in classroom settings (partly based on the Maltti programme procedures) before the follow-up assessment. The probable leak of training to the control group was unfortunate, and it is possible that it affected the results of this group in the follow-up phase. This kind of leak can be difficult to avoid after training in the intervention method has happened in small and active educational communities.

The present study raises a few research questions that are worth further consideration. First, the effects of an intervention that combines small-group behavioural, cognitive, and skills training with classroom intervention should be studied further to see if this kind of extension of intervention would have an impact on the power, generalization, and maintenance of the effects. Second, a better understanding of the factors affecting treatment response is needed (Langberg, Becker, Epstein, Vaughn, \& Girio-Herrera, 2013) in order to know to whom the intervention should be targeted and which circumstances are optimal for it. Third, there is a need for more knowledge regarding the effects of the intervention on academic skills, and therefore other areas of academic skills should be included. Lastly, the children's own views and opinions on the acceptability of the intervention should be included. This kind of information would expose how children experience the intervention and how these experiences correlate with the intervention outcomes.

To conclude, the results of the current study are encouraging and support the idea that combining behavioural and cognitive intervention with skills training and providing it in the natural everyday context is an efficient treatment approach. The intervention used in this study was carried out in schools and the effects of the intervention were examined in the school context. The results showed that the intervention improved the behaviour and functioning in a classroom setting of children with moderate symptoms of attention and EF deficit. The positive intervention effects were also evaluated by means of academic ability tests. The findings suggest that the intervention effects did generalize to other settings and to 
non-practiced skills (i.e., fluency). It was not assumed that the intervention could remove attention problems. However, it does seem that improving skills related to on-task functioning and learning may underlie the observed generalization of treatment outcomes. As Miller and Hinshaw (2012) have stated, even when an intervention fails to normalize the underlying deficits, a successful intervention can facilitate adaptive functioning and the longterm course of development.

\section{References}

Aase, H., \& Sagvolden, T. (2006). Infrequent, but not frequent, reinforcers produce more variable responding and deficient sustained attention in young children with attentiondeficit/hyperactivity disorder (ADHD). Journal of Child Psychology and Psychiatry, 47(5), 457-471. doi: 10.1111/j.1469-7610.2005.01468.x.

Abikoff, H. (2009). ADHD psychosocial treatments: generalization reconsidered. Journal of Attention Disorders, 13(3), 207-210. doi: 10.1177/1087054709333385.

Abikoff, H., Nissley-Tsiopinis, J., Gallagher, R., Zambenedetti, M., Seyffert, M., Boorady, R., \& McCarthy, J. (2009). Effects of MPH-OROS on the organizational, time management, and planning behaviors of children with ADHD. Journal of the American Academy of Child \& Adolescent Psychiatry, 48(2), 166-175.

Abikoff, H., Gallagher, R., Wells, K. C., Murray, D. W., Huang, L., Lu, F., \& Petkova, E. (2013). Remediating organizational functioning in children with ADHD: Immediate and long-term effects from a randomized controlled trial. Journal of consulting and clinical psychology, 81(1), 113-128. doi: 10.1037/a0029648.

ADHD (online). Current Care Guidelines. Working group set up by the Finnish Medical Society Duodecim, Finnish Association of Pediatric Neurology, Finnish Association of Youth Psychiatry, and Finnish Association of Child Psychiatry, 2013 (referred November 21, 2016). Available online at: www.kaypahoito.fi. 
Aunola, K, \& Räsänen, P. (2007). The 3-minutes Basic Arithmetic Test. Unpublished test material. Jyväskylä, Finland: Niilo Mäki Instituutti.

Barkley, R. A. (1997). Behavioral inhibition, sustained attention, and executive functions: constructing a unifying theory of ADHD. Psychological Bulletin, 121(1), 65. doi: 10.1037/0033-2909.121.1.65.

Best, J. R., Miller, P. H., \& Naglieri, J. A. (2011). Relations between executive function and academic achievement from ages 5 to 17 in a large, representative national sample. Learning and individual differences, 21(4), 327-336. doi: 10.1016/j.lindif.2011.01.007.

Björn, P. M., Aro, M. T., Koponen, T. K., Fuchs, L. S., \& Fuchs, D. H. (2015). The many faces of special education within RTI frameworks in the United States and Finland. Learning Disability Quartely, 1-9. Advance online publication. doi:10.1177/0731948715594787.

Das, J. P., Parrila, R. K., \& Papadopoulos, T. C. (2000). Cognitive education and reading disability. Experience of mediated learning: An impact of Feuerstein's theory in education and psychology, 274-291.

Deaño, M. D., Alfonso, S., \& Das, J. P. (2015). Program of arithmetic improvement by means of cognitive enhancement: An intervention in children with special educational needs. Research in developmental disabilities, 38, 352-361. doi: 10.1016/j.ridd.2014.12.032.

Diamond, A. (2013). Executive functions. Annual review of psychology, 64, 135-168.

DuPaul, G. J., Eckert, T. L., \& Vilardo, B. (2012). The effects of school-based interventions for attention deficit hyperactivity disorder: a meta-analysis 1996-2010. School Psychology Review, 41(4), 387-412. doi: 10.1037/e622412010-001.

Evans, S.W., Owens, J., \& Bunford, N. (2014). Evidence-based psychosocial treatments for children and adolescents with attention-deficit/hyperactivity disorder. Journal of 
Clinical Child \& Adolescent Psychology, 43 (4), 527-551. doi:

$10.1080 / 15374416.2013 .850700$.

Fabiano, G. A., Pelham, W. E., Coles, E. K., Gnagy, E. M., Chronis-Tuscano, A., \& O'Connor, B. C. (2009). A meta-analysis of behavioral treatments for attentiondeficit/hyperactivity disorder. Clinical psychology review, 29(2), 129-140. doi: 10.1016/j.cpr.2008.11.001.

Gordon, M., Antshel, K., Faraone, S., Barkley, R., Lewandowski, L., Hudziak, J. J., Biederman, J. \& Cunningham, C. (2006). Symptoms Versus Impairment: The Case for Respecting DSM-IV's Criterion D. Journal of Attention Disorders, 9(3), 465-475. doi: $10.1177 / 1087054705283881$.

Hayes, A. F. (2013). Introduction to mediation, moderation, and conditional process analysis: A regression-based approach. New York: Guilford Press. doi: 10.1111/jedm. 12050 .

Hinshaw, S. P., \& Arnold, L. E. (2015). Attention-deficit hyperactivity disorder, multimodal treatment, and longitudinal outcome: evidence, paradox, and challenge. Wiley Interdisciplinary Reviews: Cognitive Science, 6(1), 39-52. doi: 10.1002/wcs. 1324. Jacob, R., \& Parkinson, J. (2015). The Potential for School-Based Interventions That Target Executive Function to Improve Academic Achievement: A Review. Review of Educational Research, 85(4), 512-552. doi: 10.3102/0034654314561338.

Kearns, D. M., \& Fuchs, D. (2013). Does cognitively focused instruction improve the academic performance of low-achieving students? Exceptional Children, 79(3), 263.

Klenberg, L., Jämsä, S., Häyrinen, T., Lahti-Knuuttila, P., \& Korkman, M. (2010). The Attention and Executive Function Rating Inventory (ATTEX): Psychometric properties and clinical utility in diagnosing ADHD subtypes. Scandinavian journal of psychology, 51(5), 439-448. doi: 10.1111/j.1467-9450.2010.00812.x. 
Koponen, T., \& Mononen, R. (2010a). The 2-minutes addition fluency test. Unpublished test material. Jyväskylä, Finland: Niilo Mäki Instituutti.

Koponen, T., \& Mononen, R. (2010a). The 2-minutes subtraction fluency test. Unpublished test material. Jyväskylä, Finland: Niilo Mäki Instituutti.

Langberg, J. M., Arnold, L. E., Flowers, A. M., Epstein, J. N., Altaye, M., Hinshaw, S. P., Swanson, J. M., Kotkin, R., Simpson, S., \& Molina, B. S. G. (2010). Parent-reported homework problems in the MTA study: Evidence for sustained improvement with behavioral treatment. Journal of Clinical Child \& Adolescent Psychology, 39(2), 220233. doi: $10.1080 / 15374410903532700$.

Langberg, J. M., Epstein, J. N., Becker, S. P., Girio-Herrera, E., \& Vaughn, A. J. (2012). Evaluation of the Homework, Organization, and Planning Skills (HOPS) intervention for middle school students with ADHD as implemented by school mental health providers. School Psychology Review, 41(3), 342-364.

Langberg, J. M., Becker, S. P., Epstein, J. N., Vaughn, A. J., \& Girio-Herrera, E. (2013). Predictors of response and mechanisms of change in an organizational skills intervention for students with ADHD. Journal of child and family studies, 22(7), 10001012. doi: 10.1007/s10826-012-9662-5.

Leppänen, U., Aunola, K., \& Nurmi, J. E. (2005). Beginning readers' reading performance and reading habits. Journal of Research in Reading, 28(4), 383-399. doi: 10.1111/j.1467-9817.2005.00281.x.

Lindeman, J. (1998). Allu - Ala-asteen lukutesti [Reading test for primary school]. Turku, Finland: University of Turku.

Linnakylä, P., Välijärvi, J., \& Arffman, I. (2011). Finnish basic education: When equity and excellence meet. Equity and excellence in education.. In K. Van den Branden, P. Van Avermaet, \& M. Van Houtte (Eds.), Equity and excellence in 
education: Towards maximal learning opportunities for all students (pp. 190-214). New York, NY: Routledge.

Loe, I. M., \& Feldman, H. M. (2007). Academic and educational outcomes of children with ADHD. Journal of pediatric psychology, 32(6), 643-654. doi: 10.1093/jpepsy/js1054.

Milch-Reich, S., Campbell, S. B., Pelham Jr, W. E., Connelly, L. M., \& Geva, D. (1999). Developmental and individual differences in children's on-line representations of dynamic social events. Child Development, 70(2), 413-431. doi: 0009-3920/99/70020011

Miller, M., \& Hinshaw, S. P. (2012). Attention-Deficit/Hyperactivity disorder. In Kendall P. C. (Eds.), Child and Adolescent Therapy (pp. 61-91). New York: The Guilford Press. Murphy, K. R., Barkley, R. A., \& Bush, T. (2002). Young adults with attention deficit hyperactivity disorder: subtype differences in comorbidity, educational, and clinical history. The Journal of nervous and mental disease, 190(3), 147-157. doi: 10.1097/00005053-200203000-00003.

Owens, E. B., Hinshaw, S. P., Kraemer, H. C., Arnold, L. E., Abikoff, H. B., Cantwell, D. P., Conners, C. K., Elliot, G., Greenhill, L. L., Hechtman, L., Hoza, B., Jensen, P. S., March, J. S., Newcorn, J. H., Pelham, W. E., Severe, J. B., Swanson, J. M., Vitiello, B., Wells, K. C., \& Wigal, T. (2003). Which treatment for whom for ADHD? Moderators of treatment response in the MTA. Journal of consulting and clinical psychology, 71(3), 540. doi: 10.1037/0022-006x.71.3.540.

Paananen, M., Heinonen J., Knoll J., Leppänen U., \& Närhi V. (2011). Kummi 8. Malttitarkkaavuuden ja toiminnanohjauksen ryhmäkuntoutus. [Maltti-Group based intervention of deficits in attention and executive functions]. Jyväskylä: NMI.

Pelham Jr, W. E., \& Fabiano, G. A. (2008). Evidence-based psychosocial treatments for 
attention-deficit/hyperactivity disorder. Journal of Clinical Child \& Adolescent Psychology, 37(1), 184-214. doi: 10.1080/15374410701818681

Polanczyk, G., de Lima, M. S., Horta, B. L., Biederman, J., \& Rohde, L. A. (2007). The worldwide prevalence of ADHD: a systematic review and metaregression analysis. The American journal of psychiatry, 164(6), 942-948. doi: 10.1176/ajp.2007.164.6.942.

Rapport, M. D., Orban, S. A., Kofler, M. J., \& Friedman, L. M. (2013). Do programs designed to train working memory, other executive functions, and attention benefit children with ADHD? A meta-analytic review of cognitive, academic, and behavioral outcomes. Clinical psychology review, 33(8), 1237-1252. doi: 10.1016/j.cpr.2013.08.005.

Räsänen, P., Salminen, J., Wilson, A. J., Aunio, P., \& Dehaene, S. (2009). Computer-assisted intervention for children with low numeracy skills. Cognitive Development, 24(4), 450472. doi: 10.1016/j.cogdev.2009.09.003.

Salmi, P., Eklund, K., Järvisalo, E., \& Aro, M. (2011). LukiMat - Oppimisen arviointi: Lukemisen ja kirjoittamisen tuen tarpeen tunnistamisen välineet 2. luokalle. Käyttäjän opas. [Assessment of learning: Reading and writing assessment materials. Users guide.] (Available on http://www.lukimat.fi/lukimat-oppimisen-arviointi/materiaalit/tuentarpeen-tunnistaminen/21k/lukeminen/kayttajan-opas).

Schultz, B. K., Storer, J., Watabe, Y., Sadler, J., \& Evans, S. W. (2011). School-based treatment of attention-deficit/hyperactivity disorder. Psychology in the Schools, 48(3), 254-262. doi: 10.1002/pits.20553.

Sonuga-Barke, E. J. (2002). Psychological heterogeneity in AD/HD—a dual pathway model of behaviour and cognition. Behavioural brain research, 130(1), 29-36. doi: $10.1016 / \mathrm{s} 0166-4328(01) 00432-6$. 
Sonuga-Barke, E. J., Brandeis, D., Cortese, S., Daley, D., Ferrin, M., Holtmann, M., ... \& Dittmann, R. W. (2013). Nonpharmacological interventions for ADHD: systematic review and meta-analyses of randomized controlled trials of dietary and psychological treatments. American Journal of Psychiatry, 170(3), 275-289.

Toplak, M. E., Connors, L., Shuster, J., Knezevic, B., \& Parks, S. (2008). Review of cognitive, cognitive-behavioral, and neural-based interventions for AttentionDeficit/Hyperactivity Disorder (ADHD). Clinical Psychology Review, 28, 801-823. doi: 10.1016/j.cpr.2007.10.008. 
Table 1. Treatment features of the Maltti intervention

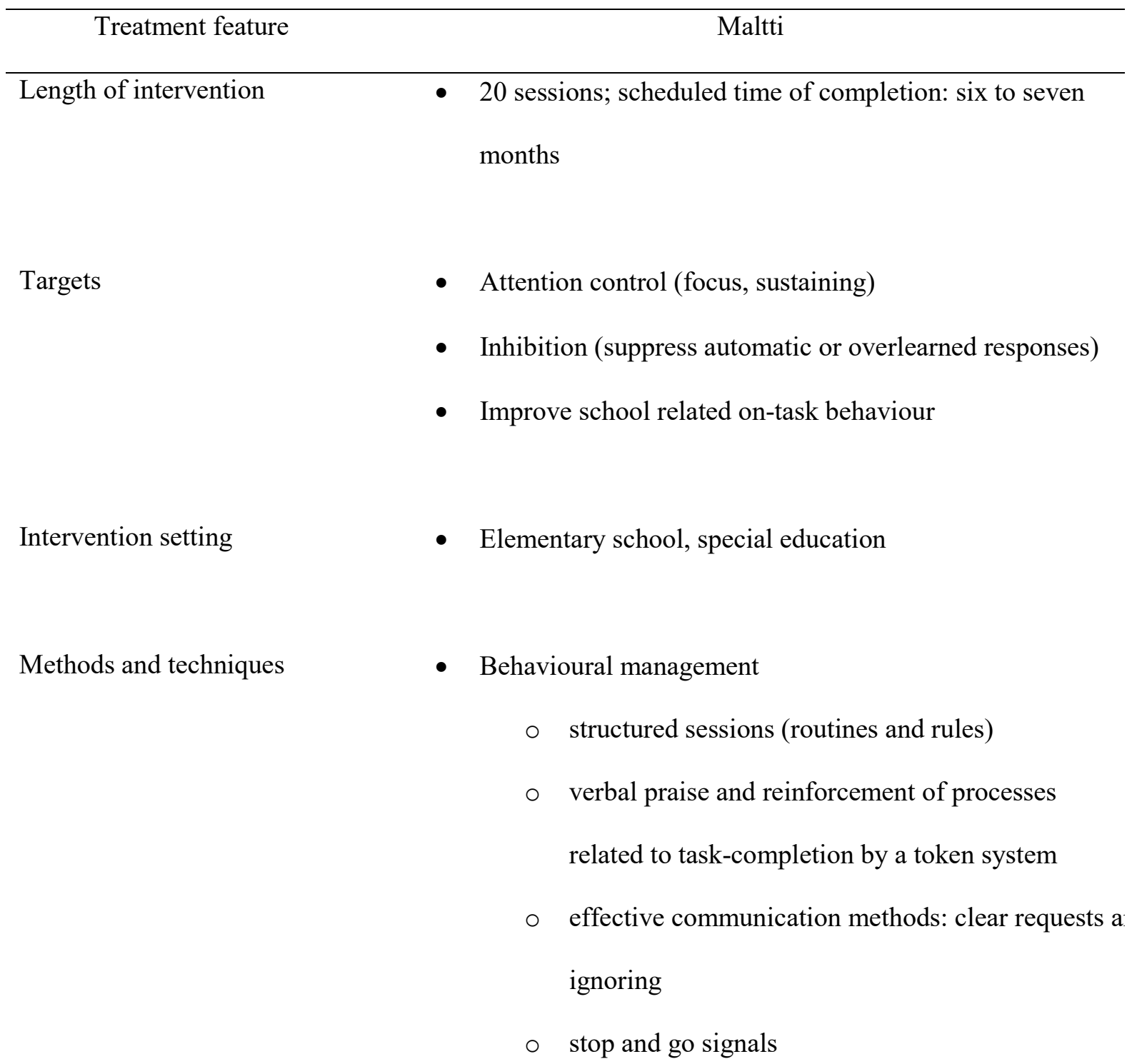

- Cognitive and learning-related executive skills building

$\circ$ exercises demanding sustained attention and control of focus

- strategy training and suppression of automatic or overlearned responses: focusing on relevant information, managing information and materials, planning completion of tasks 
$\circ$ modelling

$\circ$ scaffolding and verbalization

Materials and practices

Assisting materials

Session content (four topics)
- Visual and auditory attention tasks (e.g. visual searching tasks, auditory repetition tasks)

- Visual and logical problem-solving tasks (e.g. organising card series, reasoning of the rules in visual problemsolving tasks)

- Social problem-solving tasks (e.g. strategy use in social/peer problem situations)

- Academic skills (e.g. strategy use in reading comprehension, mathematical verification, and problem solving tasks)

- Games (board games and card games)

- Psycho-educative stories

- I. Warm-up and review of previously learned skills and presentation of new materials and skills

- II. Practice of required skills and practice with materials and tasks

- III. Feedback

- IV. Game or play practice 
Table 2. Attrition of participants and data obtained (from ATTEX and academic tests) for analysis

\begin{tabular}{|c|c|c|c|c|c|c|c|c|}
\hline & \multirow{3}{*}{$\begin{array}{c}\mathrm{n} \text { initial } \\
\text { stage }\end{array}$} & \multicolumn{5}{|c|}{ Missing data } & \multicolumn{2}{|c|}{ Data for analysis } \\
\hline & & Drop- & Poor & Pre & Post & Follow & n Pre vs. & n Pre vs. \\
\hline & & out & fidelity & & & -up & Post & Follow-up \\
\hline ATTEX & & \multicolumn{5}{|c|}{ Teacher Questionnaire } & & \\
\hline - Intervention group & 62 & 2 & 9 & 4 & 1 & 1 & 46 & 45 \\
\hline - Waitlist control group & 28 & 0 & - & 0 & 2 & 0 & 26 & 26 \\
\hline \multicolumn{2}{|l|}{ Academic tests } & \multicolumn{5}{|c|}{ Reading / Math } & & \\
\hline - Intervention group & 49 & 2 & 9 & $0 / 0$ & $1 / 1$ & $2 / 3$ & $37 / 37^{\mathrm{a}}$ & $35 / 34^{\mathrm{a}}$ \\
\hline - Waitlist control group & 28 & 0 & - & $0 / 0$ & $0 / 0$ & $0 / 0$ & $28 / 28$ & $28 / 28$ \\
\hline
\end{tabular}

Note. ${ }^{\text {a }}$ Intervention group $\mathrm{n}$ in ANOVA analyses, reading / math. 
Table 3. Comparison of baseline mean values of the groups included in the analyses

\begin{tabular}{cccc}
\hline Intervention & Waitlist control group & Mean difference \\
group & $(\mathrm{n}=28)$ \\
Variables & $(\mathrm{n}=46)$ & \\
\cline { 2 - 3 } & $\mathrm{M}(\mathrm{SD})$ & \\
\hline
\end{tabular}

Age (month)

ATTEX analyses

$112(13.44)$

Academic test analyses

$113(14.78)$

Grade level

ATTEX analyses

Academic test analyses

ATTEX total score

Reading scores

Word Recognition Test

Luksu Fluency Test

Math scores

Arithmetic Fluency Test

$10.97(5.26)$

Basic Arithmetic Test

Parents education

Mother

$3.33(0.90)$

$3.25(0.86)$

Father percentage
$111(16.35)$

$113(18.31)$ ns.

ns.
$54.03(39.42)$

$20.73(10.29)$

$2.80(1.05) \quad 2.84(1.31) \quad$ ns.

$3.00(1.26) \quad$ ns.

$59.62(24.21) \quad$ ns.

$51.04(36.77) \quad$ ns.

$17.07(10.64) \quad$ ns.

percentage

comparison of

proportions

\begin{tabular}{lccc}
\hline Diagnoses of ADHD & $17 \%$ & $11 \%$ & ns. \\
ADHD medication & $13 \%$ & $7 \%$ & ns.
\end{tabular}

Note. In ATTEX analyses, waitlist control group $n=26$ and in academic test analyses intervention group $n=37$. 
Table 4. ATTEX scores at pre-, post-, and follow-up assessments

\begin{tabular}{|c|c|c|c|c|c|c|}
\hline \multirow[b]{2}{*}{ Variable } & \multicolumn{3}{|c|}{ Intervention group $(\mathrm{n}=46)^{\mathrm{a}}$} & \multicolumn{3}{|c|}{ Waitlist control group $(n=26)$} \\
\hline & Pre M (SD) & Post M (SD) & Follow-up M (SD) & Pre M (SD) & Post M (SD) & Follow-up M (SD) \\
\hline ATTEX total score & $52.20(21.80)$ & $41.83(22.65)$ & $42.34(25.33)$ & $59.62(24.21)$ & $57.77(22.33)$ & $53.15(27.00)$ \\
\hline
\end{tabular}

Note. ${ }^{\text {a }}$ In the follow-up assessment, $\mathrm{N}=45$, the pre-assessment score of 45 subjects $=51.24$ (21.05). Higher scores indicate greater symptom severity. 
Table 5. Academic test results

\begin{tabular}{lccccccc}
\hline & \multicolumn{3}{c}{ Intervention group $(\mathrm{n}=37)^{\mathrm{a}}$} & & & \multicolumn{3}{c}{ Waitlist control group (n=28) } \\
\cline { 2 - 3 } & Pre M (SD) & Post M (SD) & Follow-up M (SD) & & Pre M (SD) & Post M (SD) & Follow-up M (SD) \\
\hline Word Recognition & $54.03(39.42)$ & $77.14(49.28)$ & $84.26(50.84)$ & & $51.03(36.77)$ & $64.14(35.20)$ & $72.32(39.73)$ \\
Reading Fluency & $20.73(10.29)$ & $24.73(8.79)$ & $26.23(10.93)$ & & $17.07(10.64)$ & $21.57(9.97)$ & $25.75(11.20)$ \\
Arithmetic Fluency & $41.43(21.59)$ & $53.68(25.00)$ & $56.24(27.72)$ & & $39.56(16.00)$ & $45.29(17.13)$ & $51.18(23.95)$ \\
Basic Arithmetic & $10.97(5.25)$ & $12.23(4.75)$ & $14.35(5.07)$ & & $9.42(5.29)$ & $11.46(4.85)$ & $12.68(6.40)$
\end{tabular}

Note. ${ }^{\text {a }}$ In the follow-up assessment, the number of participants was 35 in the reading tests and 34 in the mathematical tests, and pre-assessment values: Word Recognition ( $\mathrm{n}=35) \mathrm{M}=53.17$ (39.73), Reading Fluency ( $\mathrm{n}=35) \mathrm{M}=20.63$ (10.57), Arithmetic Fluency ( $=34) \mathrm{M}=41.74$ (22.25) and Basic Arithmetic $(\mathrm{n}=34) \mathrm{M}=11.09$ (5.48). 